\title{
ANÁLISE DE ALGUNS TRAÇOS FONOLÓGICOS GRADUAIS NA ESCRITA SOB A PERSPECTIVA DA SOCIOLINGUÍSTICA EDUCACIONAL
}

\author{
ANÁLISIS DE ALGUNOS RASGOS FONOLÓGICOS GRADUALES EN LA ESCRITURA \\ DESDE LA PERSPECTIVA DE LA SOCIOLINGÜÍSTICA EDUCATIVA
}

\author{
ANALYSIS OF SOME GRADUATE PHONOLOGICAL TRACES IN WRITING FROM THE \\ PERSPECTIVE OF EDUCATIONAL SOCIOLINGUISTICS
}

\author{
Marcus Garcia de SENE $^{1}$ \\ Egisvanda Isys de Almeida SANDES ${ }^{2}$
}

\begin{abstract}
RESUMO: A escola brasileira enfrenta desafios, sobretudo no que diz respeito à escrita ou, mais especificamente, ao aprendizado da norma padrão difundida de maneira intensiva nos manuais escolares. No processo de ensino/aprendizagem da modalidade escrita, ignora-se a influência da oralidade, de que maneira os hábitos da fala são frequentemente representados nos textos escolares e como estes refletem variáveis comuns no falar do Português Brasileiro (PB). Sendo assim, o presente artigo objetiva analisar traços fonológicos graduais na escrita presentes em redações escolares do $6^{\circ}$ ano segundo os princípios da Sociolinguística Educacional (BORTONI-RICARDO, 2005). Foram selecionados e analisados os três tipos de desvios mais frequentes de acordo com a pesquisa de Sene (2018), através dos quais observou-se que os princípios da Sociolinguística Educacional são cruciais para compreender que tais desvios não devem ser vistos como fonte de conflito no espaço escolar, mas sim como oportunidade de reflexão sobre a importância da variação linguística e do saber sociolinguístico.
\end{abstract}

PALAVRAS-CHAVE: Ensino/aprendizagem da escrita. Português do Brasil. Oralidade na escrita. Sociolinguística educacional. Traços fonológicos graduais.

RESUMEN: La escuela brasileña enfrenta desafíos, especialmente en lo que respecta a la escritura o, más específicamente, al aprendizaje de la norma estándar que se difunde intensamente en los libros de texto escolares. Lo que se ignora en el proceso de enseñanza / aprendizaje de la modalidad escrita es la influencia de la oralidad, cómo los hábitos del habla aparecen con frecuencia en los textos escolares y cómo reflejan rasgos lingüísticos variables comunes en el habla del portugués de Brasil (PB). Por lo tanto, este artículo tiene como objetivo discutir acerca de los rasgos fonológicos graduales en la escritura de niños del sexto año de la Educación Básica según los principios de la Sociolingüística Educativa (BORTONI-RICARDO, 2005). Se seleccionaron y analizaron las tres desviaciones observadas como más frecuentes en la investigación de Sene (2018), a través de las cuales se observó que los principios de la Sociolingüística Educativa son

\footnotetext{
${ }^{1}$ Universidade Estadual Paulista (UNESP), Araraquara - SP - Brasil. Doutorando em Linguística e Língua Portuguesa. Membro colaborador do GT de Sociolinguística da ANPOLL e sócio da Associação Brasileira de Linguística (ABRALIN). ORCID: http://orcid.org/0000-0002-2715-5294. E-mail: unesp.marcus@gmail.com

${ }^{2}$ Universidade Estadual Paulista (UNESP), Araraquara - SP - Brasil. Docente da Faculdade de Ciências e Letras. Pós-doutora pela Universidad de Granada - Espanha. ORCID: http://orcid.org/0000-0003-3824-146X. Email: wandasandes2016@gmail.com
} 
cruciales para comprender que tales desviaciones no deben verse como una fuente de conflicto en el espacio escolar, sino como una oportunidad para reflexionar sobre la importancia de la variación lingüística y el conocimiento sociolingüístico.

PALABRAS CLAVE: Enseñanzalaprendizaje de la escritura. Portugués de Brasil. Oralidad en la escritura. Sociolingüística educativa. Rasgos fonológicos graduales.

ABSTRACT: The Brazilian school faces challenges, especially with regard to writing or, more specifically, to learning the standard norm that is intensively disseminated in school textbooks. What is ignored in the teaching / learning process of the written modality is the influence of orality, how speech habits are frequently represented in school texts and how they reflect variable linguistic traits common in Brazilian Portuguese (PB) speech. Thus, this article aims to discuss gradual phonological traits in writing present in 6th grade school essays according to the principles of Educational Sociolinguistics (BORTONI-RICARDO, 2005). The three most frequent deviations according to the research by Sene (2018) were selected and analyzed, through which it was observed that the principles of Educational Sociolinguistics are crucial to understand that such deviations should not be seen as a source of conflict in the school space, but as an opportunity for reflection on the importance of linguistic variation and sociolinguistic knowledge.

KEYWORDS: Teaching/learning of writing. Brazilian Portuguese. Orality in writing. Educational sociolinguistics. Gradual phonological traits.

\section{Introdução}

Grande parte dos alunos sofre com o processo de exclusão por parte da escola, mesmo no início da alfabetização, por não apresentarem resultados suficientes no domínio de habilidades que envolvem a leitura e a escrita $^{3}$ (GOMES, 2008; SENE, 2018; SENE; BARBOSA, 2019). São inúmeros os motivos pelos quais os alunos apresentam dificuldades, especialmente no domínio pouco proficiente da modalidade escrita da língua, alguns dos quais serão discutidos neste artigo: (a) a emblemática noção de norma padrão, (b) o desconhecimento da relação entre a fala e a escrita e (c) o ensino descontextualizado e desatualizado das variedades da língua.

Seguir uma trajetória educacional em que se prioriza um ensino descontextualizado da escrita, colocando essa modalidade como superior à modalidade da fala, tem sido o maior equívoco da escola. Ao tratar sobre a percepção do contexto social, Moreno Fernández (2012)

${ }^{3}$ A Avaliação Nacional da Alfabetização (ANA), realizada em 2016 com mais de 2 milhões de crianças, aponta que $55 \%$ dos alunos tiveram desempenho insuficiente em leitura e $34 \%$ em escrita. Disponível em: https://envolverde.cartacapital.com.br/dificuldades-de-leitura-e-escrita-expoem-fragilidade-dos-processos-dealfabetizacao/. Acesso em: jan. 2020. 
comenta que tanto a linguística laboviana quanto a maioria das disciplinas de base social desenvolvidas nos Estados Unidos durante a segunda metade do século XX:

"tem seu fundamento no funcionalismo estrutural de Pason (1937), Kingsley Davis e Wilbert Moore (1945) ou Robert Merton (1949) e tem o conceito de "consenso" como um de seus fundamentos. As teorias do consenso consideram que as normas e os valores comuns são fundamentais para a sociedade e que a ordem social se baseia em um acordo tácito que faz com que as mudanças sociais sejam lentas e organizadas. Este consenso ocorre também na língua, pois a conduta linguística responde o seguimento das normas que afetam todos os falantes por seu pertencimento a uma comunidade ou um grupo. (MORENO FERNÁNDEZ, 2012, p. 43, tradução nossa).

Nesse sentido, segundo o autor, surgem também

as teorias do conflito, de raiz marxista, que indicam o predomínio de uns grupos sociais sobre outros e explicam a ordem como consequência da manipulação e do controle por parte dos grupos dominantes sobre os dominados, o que pode provocar mudanças sociais rápidas e desorganizadas. (MORENO FERNÁNDEZ, 2012, p. 43-44, tradução nossa).

E tal manipulação é comum também no que se refere ao uso linguístico, pois a língua "é elemento substancial para a cultura, parte essencial de sua natureza e veículo de sua expressão" (MORENO FERNÁNDEZ, 2012, p. 43, tradução nossa).

Seguindo-se essas observações, há uma relação conflituosa entre a oralidade e a escrita e o desapreço da primeira modalidade no processo de ensino, conforme já discutiram diversos autores (MOLLICA, 2000; MARCUSCHI, 2001; SENE; ORANGES, 2017; HENRIQUE; HORA, 2016). No entanto, ignorar o fato de que há mais confluências do que divergências entre ambas as modalidades, é desconsiderar a percepção do contexto social, sobretudo a configuração da língua nos espaços e características que a conformam. Consoante com Moreno Fernández (2012), Fernández Marrero (2004) menciona que:

No discurso escolar e acadêmico, a norma é fixada através de afirmações explícitas e pressuposições implícitas. No primeiro caso, o das afirmações explícitas, o padrão mais comum é que existem 'dois tipos de uso: um bom e um mau', onde a dualidade asserção/negação é óbvia; no segundo, o das pressuposições implícitas, o padrão discursivo que costuma se apresentar é do tipo 'tal uso é correto (elegante, aceitável, culto)', o que faz com que se assuma a existência de outros não corretos, não elegantes, não aceitável, não cultos. ${ }^{4}$ (FERNÁNDEZ MARRERO, 2004, p. 93, tradução nossa).

4 "En el discurso escolar y académico, la norma queda fijada a través de afirmaciones explícitas y de presuposiciones implícitas. En el primer caso, el de las transformaciones explícitas, el patrón más común es que 'existen dos tipos de uso: uno bueno y uno malo', donde la dualidad aserción/negación es obvia; en el segundo, 
Dentre aqueles usos considerados não elegantes, não aceitáveis e não cultos no ambiente escolar, estão os desvios ${ }^{5}$ da norma padrão, muitos dos quais são diagnosticados em redações escolares como reflexos de fenômenos variáveis frequentes no falar do Português Brasileiro que acabam representando regras variáveis graduais. Verifica-se, portanto, que no processo de ensino e aprendizagem sistematizado pela escola há uma centralização no comportamento linguístico normatizado e fundamentado no conceito de norma padrão, o que ignora a importância de se compreender o hábito da fala para a escrita como uma das explicações do surgimento de grande parte dos desvios linguísticos. Tal comportamento acaba colocando esses desvios na dimensão da dualidade do "bom" e "mau" mencionada por Fernández Marrero (2004), portanto, como os desvios linguísticos são representantes do que se distancia do padrão, são quase sempre colocados como o que deve ser combatido pela escola. Dito isso, e considerando-se que em ortografia muitos aspectos são frutos de um acordo social, dado que foram definidos de forma arbitraria (MORAIS, 2003), inclusive no que tange às regras mais básicas, deve-se compreender que "quando vai escrever, o aluno reflete sobre o que está fazendo e vai buscar subsídios na língua oral e nos conhecimentos que está adquirindo sobre a estrutura da língua escrita para construir hipóteses sobre a forma correta de escrever" e que o processo de confecção dessas hipóteses "vai se tornando mais eficiente à medida que os alunos avançam na aprendizagem da escrita" (BORTONI-RICARDO; OLIVEIRA, 2013, p. $55)$.

Se é na modalidade oral que o aluno vai buscar subsídios e hipóteses de como é determinada forma escrita, ocorre naturalmente a influência de uma modalidade na outra, neste caso da oralidade na escrita. Dessa forma, antes dos alunos conhecerem mais sobre a "norma padrão" - estabilizadora e unificadora -, exigida pelos manuais escolares em contexto de escrita formal, devem compreender a influência dos hábitos da fala na escrita e depreendam, sobretudo, o papel de ambas as modalidades.

Sendo assim, neste artigo objetiva-se discutir sobre variação, oralidade e ensino a partir da análise de alguns desvios linguísticos extraídos de redações escolares do $6^{\circ}$ ano, decorrentes da fala, especificamente aqueles que ilustram traços fonológicos graduais. Para tanto, o texto possui uma estrutura que se inicia com a apresentação de um aporte teórico no qual há uma exposição inicial sobre os princípios da sociolinguística educacional e uma

el de las presuposiciones implícitas, el patrón discursivo que suele presentarse es del tipo 'tal uso es correcto (elegante, aceptable, culto)', lo que hace sobrentender la existencia de otros no correctos, no elegantes, no aceptables, no cultos."

5 A noção de "desvios" ortográficos apresentada neste trabalho não abrange a possibilidade de transgressão do código aos usuários da língua, mas sim defende e respeita que, por existir diferentes modos de escrever o mesmo, todos são válidos e, mormente, representam tentativas não padronizadas da modalidade escrita. Estaremos, portanto, ainda diante de transgressões do padrão pré-estabelecido, o que reforça a importância de aprimorar ou até substituir tais ocorrências. 
discussão sucinta sobre a influência da fala na escrita; em seguida, traz uma análise das redações escolares selecionadas ${ }^{6}$ e, por fim, delineia algumas considerações que finalizam o artigo.

\section{Noções básicas de Sociolinguística Educacional}

A concepção de que a variação existe e é parte essencial de todas as línguas naturais, sendo portanto inerente ao sistema linguístico, não se discute dentro do escopo da sociolinguística. Labov (1972), por exemplo, debruçou-se sobre o viés investigativo da relação entre a língua e a $\operatorname{sociedade}^{7}$ e, ao longo de quase 60 anos de pesquisa sociolinguística, fundou e consagrou que as línguas são naturalmente heterogêneas e que esta heterogeneidade é regulada e governada por restrições linguísticas e não linguísticas.

Esse caráter dinâmico da língua sistematizado nos estudos sociolinguísticos oferece uma grande contribuição para a reflexão e a conscientização dos professores, alunos e da comunidade em geral sobre o preconceito linguístico, assim como a compreensão dos fenômenos linguísticos variáveis. A Língua Portuguesa no Brasil, por exemplo, constitui-se de muitas variedades e, mesmo havendo uma aparente "unidade linguística" e apenas uma língua nacional, constata-se a variação em diversos níveis da estrutura linguística, o que reforça a ideia de que a variação linguística vai existir independente de qualquer ação normativa.

A intersecção dos estudos sociolinguísticos com o ensino de língua materna ${ }^{8}$ possui como um dos objetivos a valorização das variedades linguísticas e, consequentemente, a luta contra o preconceito linguístico. Essa junção resulta em uma corrente teórico-prática, denominada Sociolinguística Educacional (SE), que busca analisar os fenômenos da variação sob os preceitos da teoria sociolinguística e, também, verificar a implicação desses fenômenos no ensino e na aprendizagem dos estudantes. Sobre sua definição e seu alcance, BortoniRicardo (2005) esclarece:

\footnotetext{
${ }^{6}$ As redações foram analisadas na dissertação de Mestrado de Sene (2018), pesquisa na qual uma discussão mais detalhada sobre variação, oralidade e ensino é apresentada.

${ }^{7}$ Todo linguista reconhece que a língua é um fato social, mas nem todos dão a mesma ênfase a esse fato. Quando os linguistas escrevem sobre mudança linguística, encontramos um grau muito diferente de preocupação com o contexto social em que essas mudanças ocorrem. Alguns ampliam sua visão para incluir uma ampla gama de fatos sobre os falantes e seu comportamento extralinguístico, enquanto outros estreitam sua visão para excluir o máximo possível. (LABOV, 2008, p. 302).

${ }^{8}$ Discussões de caráter educacional, dentro do terreno da sociolinguística, foram apresentadas inicialmente por Labov (1972) em "Language in the Inner City".
} 
Denominarei Sociolinguística Educacional, de forma um pouco genérica, todas as propostas e pesquisas sociolinguísticas que tenham por objetivo contribuir para o aperfeiçoamento do processo educacional, principalmente na área do ensino de língua materna. (BORTONI-RICARDO, 2005, p. 128).

Com esse desdobramento da Sociolinguística, tomá-la apenas como sinônimo de análise linguística pura dos fenômenos da variação linguística, restringiria a essência multifacetada e interdisciplinar dessa ciência. Sobre tal aspecto, Bortoni-Ricardo (2005) acrescenta:

\footnotetext{
Não defendemos a variação per se, mas sim a análise do processo interacional, na qual se avalia o significado que a variação assume. A atenção do estudioso deve estar voltada para os padrões de emprego da variação e para os significados que essa tem no processo interacional dos atores ali envolvidos. Os significados que a variação assume podem variar muito. Para alguns alunos, por exemplo, o uso do dialeto vernáculo pode ser indicador de inserção numa cultura de rua que prezam; para outros o domínio de estilos monitorados representa prestígio. Entre os professores, do mesmo modo, haverá aqueles que atribuem valor muito negativo à variação e outros que a veem como uma característica natural dos alunos, indicadora de sua cultura. (BORTONI-RICARDO, 2005, p. 132, grifo nosso).
}

Nesse sentido, a indiferença diante das produções dos alunos (orais e/ou escritas), que apresentam variação, representa a desconsideração de aspectos importantes, especialmente porque o trabalho do professor de língua materna reside, sobretudo, a necessidade da sensibilidade linguística. O ensino de língua descontextualizado, no qual se apregoa uma perspectiva normativa de observação da língua, não tem surtido nenhum efeito do ponto de vista da funcionalidade linguística e um dos principais exemplos são os textos escritos dos alunos.

Desvios da modalidade padrão, que refletem tanto hábitos da fala para a escrita quanto desconhecimento das regras de convenção do código escrito, podem ser observados em diferentes níveis de escolarização, conforme pesquisas de estudiosos como Abaurre (1988), Baronas (2009) e Oliveira (2001). Tal aspecto leva à reflexão sobre o fato de que os educandos passam em média de 12 a 14 anos na escola (considerando-se a Educação Infantil) e seria natural, se o ensino da norma padrão fosse realizado de forma adequada, que os desvios de modalidade padrão comuns nas produções escritas dos alunos diminuíssem ou, até mesmo, não existissem mais.

Nesse sentido, a Sociolinguística Educacional mostra que trabalhar a variação não é apenas apresentar, em apenas um capítulo ou uma aula, as diferenças linguísticas que existem, 
mas também refletir sobre a questão e mostrar que tais diferenças devem ser respeitadas. Assim, o professor deve conduzir a aula de tal maneira que se alcance o respeito e a aceitação dos diversos modos de falares dos alunos (MOLLICA, 1998) e, também, promover uma prática de ensino e aprendizagem cujo objetivo seja as próprias produções dos alunos, escritas ou não. Nesse processo não se abandona a necessidade de ensino da norma padrão, mas se passa a reconhecer que esta nova variedade (a padrão) será acrescida ao vernáculo do aluno, pois essa é a forma considerada de prestígio e, portanto, exigida em diferentes esferas da sociedade.

Na escola, o esclarecimento de que novas formas linguísticas que são aprendidas não devem apagar ou sobrepor a variedade que os alunos já trazem de casa, também resulta no reconhecimento da legitimidade por trás da variedade que eles utilizam. Dessa forma, entenderão que as formas padrão são, na verdade, abstrações e unificações linguísticas cujo objetivo é a uniformização da forma de escrita. Alinhando-se a esta perspectiva, ocorrerá não só o processo de conscientização dos alunos, mas também de enriquecimento do seu dialeto, o que aumenta seu conhecimento sobre as possibilidades linguísticas. Promove-se, assim, o abandono da necessidade única de memorização de regras da gramática normativa e, consequentemente, a compreensão de que a escolha da forma de falar ou escrever deve ser adequada à cada situação comunicativa, ou seja, o domínio tanto de sua variedade linguística quanto da trabalhada na escola e das exigidas nos diversos âmbitos da sociedade.

Segundo Bortoni-Ricardo (2005), para que a escola atue conforme descrito anteriormente, deve haver a compreensão de seis princípios $^{9}$, delineados pela própria autora, para a implementação da Sociolinguística Educacional:

\section{Quadro 1 - Princípios da Sociolinguística Educacional}

1) Primeiro Princípio: a influência da escola na aquisição da língua não deve ser procurada no dialeto vernáculo dos falantes, mas em seus estilos formais, monitorados. É no campo da linguagem monitorada que as ações de planejamento linguístico têm influência. Portanto, a Sociolinguística Educacional tem como objetivo oferecer ao aluno conhecimento e habilidade nas variedades orais e escritas de prestígio, para que ele tenha acesso a diferentes práticas da cultura letrada.
2) Segundo Princípio: o caráter sociossimbólico das regras variáveis que não estão associadas à avaliação negativa pela sociedade não são objeto de estudo na escola. O objetivo da escola, ao estudar as regras variáveis associadas à avaliação negativa pela sociedade, não é inferiorizar o aluno que tem tais variantes em seu vernáculo, pelo contrário, é que ele tenha consciência dos valores sociossimbólicos de tais variantes.

${ }^{9}$ Bortoni-Ricardo (2005) dá o nome de princípios e não regras, pois princípios pressupõem noções básicas, enquanto que as regras têm função de regulamentação direta e restrita. 


\begin{tabular}{|c|c|}
\hline $\begin{array}{l}\text { 3) Terceiro Princípio: inserção da variação } \\
\text { sociolinguística na matriz social. O ensino das } \\
\text { variedades de prestígio na escola não é } \\
\text { necessariamente fonte de conflito, embora } \\
\text { possa ser fonte de discriminação das crianças } \\
\text { falantes de variedades populares. Para superar } \\
\text { essa barreira, propõe-se que os professores } \\
\text { desenvolvam uma pedagogia culturalmente } \\
\text { sensível. }\end{array}$ & $\begin{array}{l}\text { 4) Quarto Princípio: os estilos monitorados da } \\
\text { língua são reservados à realização de eventos de } \\
\text { letramento em sala de aula. Em lugar da } \\
\text { dicotomia entre "português culto" e "português } \\
\text { ruim", institui-se na escola a dicotomia entre } \\
\text { letramento e oralidade. }\end{array}$ \\
\hline $\begin{array}{l}\text { 5) Quinto Princípio: a descrição da variação } \\
\text { na Sociolinguística Educacional não pode ser } \\
\text { dissociada da análise etnográfica e } \\
\text { interpretativa do uso da variação em sala de } \\
\text { aula. O ponto de partida da Sociolinguística } \\
\text { Educacional não é a descrição da variação per } \\
\text { se, mas sim a análise minuciosa do processo } \\
\text { interacional, na qual se avalia o significado } \\
\text { que a variação assume. }\end{array}$ & $\begin{array}{l}\text { 6) Sexto Princípio: o processo de } \\
\text { conscientização crítica dos professores e alunos } \\
\text { quanto à variação e à desigualdade social que ela } \\
\text { reflete. Nesse processo, é necessário que o } \\
\text { professor não se limite a transmitir informações } \\
\text { técnicas, que são produto da pesquisa acadêmica, } \\
\text { mas que se estabeleça um efetivo diálogo com o } \\
\text { professor por meio de pesquisa, que o enriqueça e } \\
\text { o torne apto a promover uma autorreflexão e uma } \\
\text { análise crítica de suas ações. }\end{array}$ \\
\hline
\end{tabular}

Fonte: Bortoni-Ricardo (2005)

Esses princípios são delineados com vistas a proporcionar uma reflexão sobre as aulas de Português na escola e fornecer fundamentos em relação a por que, como e para que ensinar a língua. Por tais motivos, a análise de alguns desvios ortográficos nas redações escolares dos alunos apresentada neste artigo, realiza-se sob a perspectiva da Sociolinguística Educacional.

\section{Da fala para a escrita}

A escrita é um bem indispensável para o cotidiano de todos e saber escrever, hodiernamente, não só é um recurso necessário, mas importante para aqueles que desejam algum tipo de ascensão social. Desse modo, a escrita deve ser vista como essencial à própria sobrevivência (MARCUSCHI, 1997), mas não por virtudes que lhe são imanentes, posto que as formas pelas quais ela se impôs sobre a modalidade oral, por exemplo, a violência com que penetrou nos meios sociais, é que a colocou nesse status.

Apesar de que a escrita seja indispensável, o modo como tem sido apresentada aos alunos, desde a alfabetização até o fim do ciclo escolar, denota alguns equívocos pontuais e o primeiro deles, que é foco deste trabalho, é o desconhecimento da intersecção entre a fala e a escrita. A relação entre o oral e o escrito é um fato e qualquer professor de português ou de redação já se deparou com textos que apresentam desvios como, por exemplo, o apagamento do /r/ em verbos do infinitivo, como em ama x amar ou a monotongação em palavras como caxa $x$ caixa e pexe $x$ peixe. Todos eles representam hábitos comuns no falar do Português Brasileiro que acabam sendo transpostos para a escrita, principalmente graças ao continuum existente entre as duas modalidades (oral e escrito), o que é corroborado pelas palavras de 
Marcuschi (2003, p. 32), quem diz que "por serem duas modalidades de uso da língua, faz com que o aluno, ao dominar essas duas modalidades da língua, se torne bimodal, ou seja, fluente nestes dois modos de uso".

A fala como modalidade anterior à escrita justifica por que, na confluência entre ambas as modalidades, é a de maior domínio do aluno e na qual ele busca subsídios para a compreensão e o aprendizado do código pré-estabelecido que é a escrita. Sendo assim, desvios como os mencionados anteriormente, resultantes da fala para a escrita, são comuns em diferentes fases escolares.

No âmbito escolar é frequente que os professores atribuam à fala o lugar da informalidade e à escrita o papel de representante apropriada da língua devendo, portanto, ser priorizada. Essa falsa supremacia de uma modalidade sobre a outra é que tem distanciado os educadores em reconhecer o continuum existente entre a fala e a escrita. Tanto a fala quanto a escrita podem se prestar a graus de formalidade diferentes, ou seja, o quão formal ou informal é um texto/fala vai depender do contexto de produção/uso que é variável.

Desse modo, busca-se alinhar a perspectiva da Sociolinguística Educacional com a discussão realizada aqui, já que ambas permitem constar, com maior clareza, a língua como um fenômeno dinâmico. A noção de variação linguística, então, evoca que que tanto a fala quanto a escrita são variáveis e, também, que não é só a escrita que é regida por normas. Afinal, tanto a modalidade escrita quanto a falada apresentam: língua padrão/variedades nãopadrão, norma culta/norma coloquial e norma padrão/normas não padrão. Isso se dá porque a língua é, em si, é heterogênea e repleta de variação, e não um único e abstrato sistema (MARCUSCHI, 2000; MORENO FERNÁNDEZ, 2012).

\section{Aspectos metodológicos}

Os dados analisados, retirados da pesquisa de Sene (2018), compõem um corpus com 56 redações de três diferentes escolas da cidade de Araraquara (São Paulo/Brasil), totalizando 168 textos. Os informantes eram alunos do $6^{\circ}$ ano do Ensino Fundamental ${ }^{10}$ e o critério para a coleta dos dados foi o Índice de Desenvolvimento da Educação Básica (IDEB) ${ }^{11}$ de cada escola, ou seja, a Escola A era a com o maior índice, enquanto a $\mathrm{B}$ e a $\mathrm{C}$ eram a de médio e menor índice, respectivamente. Das redações analisadas, foram identificados 14 processos

${ }^{10} \mathrm{O}$ Brasil conta com três modalidades de ensino escolar: a educação básica, que é a primeira formação escolar da criança; a educação fundamental, que se inicia, obrigatoriamente, ao 6 anos de idade e dura, em média, 4 anos e, por fim, o ensino médio, que é o aprofundamento dos saberes adquiridos no ensino fundamental.

${ }^{11} \mathrm{O}$ IDEB é um indicador criado pelo governo federal para medir a qualidade do ensino nas escolas públicas. 
fonético-fonológicos que representam hábitos da fala na escrita, além de dois outros processos de segmentação de palavras que não se configuram, exclusivamente, como processos fonético-fonológicos.

Para este artigo foram selecionados apenas 3 dos processos não só por sua frequência e de aparição (conforme tabela 1) e representatividade/produtividade: por significar em a influência da fala na escrita e por serem processos fonológicos variáveis e graduais, mas também pela extensão que nos permite o artigo em questão.

Tabela 1 - Frequência absoluta dos dados

\begin{tabular}{|l|l|l|l|}
\hline Processo fonológico & Escola A & Escola B & Escola C \\
\hline Apagamento do /r/ em coda & 140 & 105 & 101 \\
\hline Monotongação & 67 & 59 & 50 \\
\hline Neutralização & 79 & 91 & 80 \\
\hline Aférese & 37 & 56 & 27 \\
\hline Alçamento das vogais pretônicas & 21 & 17 & 19 \\
\hline Apagamento de vogal & 31 & 25 & 27 \\
\hline Ditongação & 47 & 58 & 39 \\
\hline Hipersegmentação* & 29 & 34 & 26 \\
\hline Hiposegmentação* & 26 & 25 & 16 \\
\hline Monotongação & 67 & 59 & 50 \\
\hline Neutralização & 79 & 91 & 80 \\
\hline Palatalização & 19 & 16 & 10 \\
\hline Vocalização & 15 & 20 & 13 \\
\hline
\end{tabular}

Fonte: adaptado de Sene $(2018)^{12}$

A tabela 1 ilustra o número de vezes que o referido desvio linguístico - que se explica devido a um processo fonológico - foi encontrado nos textos: dos 56 textos analisados da Escola A, foram localizados 140 desvios do tipo apagamento do /r/.

Conforme já dito na seção anterior, a análise dos 3 processos fonológicos selecionados se realiza sob a perspectiva da Sociolinguística Educacional, portanto discute-se acerca do papel de quatro, dos seis princípios delineados por Bortoni-Ricardo (2005), para superação dos desvios decorrentes da fala para a escrita.

\section{Análise dos dados}

A influência da fala na escrita é um processo que ocorre por diversas razões e uma delas refere-se ao fato de que é na modalidade oral que os alunos buscam subsídios para representação da escrita, portanto, os desvios aqui analisados indicam a importância de enfocar o ensino da oralidade.

\footnotetext{
${ }^{12}$ Informações mais detalhes com uma exuberância dos fenômenos encontrados podem ser observados na dissertação de mestrado de Sene (2018).
} 
No que concerne ao apagamento do /r/, a literatura sociolinguística já mostrou que a variação do /r/ é fenômeno antigo e um exemplo é apresentado no estudo de Callou, Moraes e Leite (1998) que avaliaram a presença do referido fenômeno nas peças de Gil Vicente no século XVI. Segundo os autores, a ausência da consoante em questão era frequente na fala das pessoas comuns e, portanto, com menos ou pouco prestígio, enquanto os portugueses prestigiados e cultos tinham seus registros marcados pela presença do segmento consonântico.

Recentemente, o apagamento do /r/ deixou de ser explorado apenas na fala e ganhou espaço na análise da produção escrita produzida por alunos de diferentes níveis escolares. Esse processo fonológico variável é muito frequente na fala do brasileiro. Talvez seja o tipo de variação que mais se estendeu dentro do continuum de urbanização (BORTONIRICARDO, 2004), atingindo, dessa forma, diferentes estratos sociais, o que consiste em uma definição de uma regra variável gradual, mesmo que de maneira genérica, já que, nas palavras de Bortoni-Ricardo (2005), são graduais os fenômenos que estão presentes em várias camadas sociais, independente de seu prestígio. Nesse sentido, quando se observa a supressão do /r/, como em namora $\mathbf{x}$ namorar, sai $\mathbf{x}$ sair, anda $\mathbf{x}$ andar, nas redações dos alunos, verifica-se um hábito da fala na escrita, que também serve para reforçar a ideia de que na modalidade oral ele já não mais usa esse /r/.

O segundo fenômeno mais frequente é o de monotongação, que ocorre quando nos ditongos observa-se um apagamento da semivogal [ar], [eI], e [oひ] e tornam-se simples vogais [a], [e] e [o]. Tal como o apagamento do /r/, a monotongação tem sido foco de discussão em trabalhos de modalidade oral e escrita. Câmara-Jr (1957), em seu artigo "Erros escolares como sintomas de tendências linguísticas no português do Rio de Janeiro”, já havia apontado esse fenômeno do apagamento do glide no português, a partir do qual analisou sessenta redações de crianças de 11 a 13 anos de uma escola carioca, cujos dados mostraram uma série de características fonéticas da fala desses alunos. Desses, o pesquisador destacou a monotongação dos ditongos /ov/ e /ei/ e seus contextos precedentes e seguintes.

Este fenômeno também é um representante significativo de uma regra variável gradual, pois, como salienta Bortoni-Ricardo (2004), alguns ditongos em certos ambientes linguísticos são quase categoricamente reduzidos, mesmo em estilos formais da língua padrão urbana. Além disso, o fenômeno de monotongação é um processo "muito antigo na língua, que vem desde a evolução do latim para o português" (BORTONI-RICARDO, 2004, p. 95).

Quanto à neutralização, que consiste na perda de um traço distintivo que provoca a redução de dois fonemas a uma única unidade fonológica, é um fenômeno que, pelo alto índice de variação no sistema vocálico do Português Brasileiro, especialmente em contexto 
pretônico e postônico, faz-se muito recorrente. Além disso, como os demais fenômenos, por "não sofrer" uma estigmatização na fala, possui a característica de um fenômeno variável gradual.

Exemplos de neutralização são sapatu x sapato, qui x que, momentu x momento, ganhassi $\mathbf{x}$ ganhasse, vontadi $\mathbf{x}$ vontade (SENE, 2018), nos quais se observa a neutralização das vogais médias e altas, pois o traço que distingue /e/ e /i/, bem como /o/ e /u/ é neutralizado. No contexto brasileiro, sobre a vogal átona final, Câmara-Jr (1977) assegura que a ocorrência do processo de neutralização reduz o sistema vocálico para três vogais /i, u, a/ como nos exemplos fom[I] e $\operatorname{ral}[\mho]$.

Todos os processos ilustram que o conhecimento da realidade linguística de cada um está presente de forma veemente na escola. Além disso, os processos fonológicos variáveis observados nos desvios ortográficos das redações escolares analisadas denotam que, a forma como o educando escreve tem relação direta a experiência vivida em seu ambiente social. Por isso, à luz da Sociolinguística Educacional, o primeiro princípio delineado por BortoniRicardo (2005) se faz necessário, pois não é no vernáculo dos alunos que a escola precisa atuar, mas sim no reforço dos estilos mais formais - como as produções escritas - nos quais o ensino de língua portuguesa deve prevalecer. Nesse sentido, o papel do professor é direcionar a complementação das modalidades oral e escrita dos alunos, não para que eles substituam em seu vernáculo as formas variáveis (apagamento do /r/, monotongação, neutralização e outras), que são características de sua identidade, mas para que possam acessar diferentes práticas da cultura letrada.

O segundo princípio, que trata do caráter sócio simbólico das regras variáveis, também é importante para superação dos desvios linguísticos encontrados nas redações escolares. $\mathrm{O}$ caráter sócio-simbólico influi na avaliação negativa da sociedade sobre os fenômenos variáveis. Assim, compreender que os desvios do tipo apagamento do /r/, monotongação e neutralização sofrem avaliações negativas se torna um dos passos para que o aluno entenda dos aspectos: que a superação desse desafio deve se dar não para inferiorizar a variedade que o aluno traz de casa, mas para que ele tome consciência do valor sócio-simbólico da variação, e que aprender outra variedade (a padrão) é caminho para ascensão social.

Tal consideração ocorre quando o professor, acompanhado de uma pedagogia culturalmente sensível (ERICKSON, 1987), mostra aos educandos que não se aprende somente por aprender. As práticas de escrita, embora historicamente convencionadas, são necessárias para a circulação em diferentes esferas sociais. Além disso, a informação de que não existem formas feias ou bonitas não diz muito para aqueles que estão aprendendo a 
variedade padrão, pois a realidade cotidiana mostra que as formas linguísticas, no texto escrito ou na modalidade oral, são constantemente avaliadas. Embora essa avaliação não seja sempre negativa, ela é, por si só, uma forma de enquadrar as formas linguísticas em espectros variáveis que vão de "muito feio" a "muito bom".

Essa discussão acaba corroborando para outro princípio da SE - o quarto - que discute $\mathrm{o}$ abandono da dicotomia entre português culto x português ruim. Fenômenos como o apagamento do /r/ e a monotongação, por exemplo, não representam um "português ruim", mas sim que são fenômenos, dentro da dicotomia letramento e oralidade, comuns nas práticas orais e que devem, portanto, ser superados a medida que se avança nas práticas de letramento. Outra concepção, um dos princípios da SE que fomentaria a compreensão da dinâmica da variação no ensino de língua materna, é a inserção, consistente, da variação sociolinguística na matriz escolar e social. Este terceiro princípio, talvez o mais discutido nos vários trabalhos, sejam eles de Sociolinguística Educacional ou não, é o que provavelmente mais precise de atenção por parte dos formadores.

Sendo assim, a Sociolinguística Educacional contribui com a educação em duas frentes. Primeiro, no que se refere à ecologia linguística de uma comunidade, pois toda e qualquer variação deve ser respeitada, uma vez que não representa um "caos" linguístico, pelo contrário, é regida por regras linguísticas e sociais - como já evidenciado pela literatura sociolinguística. Segundo, porque possibilita um trabalho mais significativo com textos orais e escritos, já que ao inserir a variação na matriz social e escolar, o professor vai compreender, por exemplo, que grande parte dos desvios ortográficos apresentados pelos alunos reflete não uma deficiência ou defasagem linguística, mas sim o reflexo dos processos variáveis nas práticas escolares.

\section{Considerações finais}

Todos as observações apresentadas neste artigo demonstram que a implementação dos princípios da Sociolinguística Educacional na escola representa uma importante contribuição para a compreensão do continuum que existe entre a fala e a escrita. Seria um exemplo de que a variação linguística deve perpassar aquele único e breve capítulo sobre a variação linguística e de que a temática da variação na matriz escolar e social deve possibilitar a conscientização dos alunos de que, por exemplo, os desvios de natureza fonológica, que são frequentes nas redações escolares, não demonstram que não sabem o português: são fenômenos comuns na modalidade oral da língua e são representantes de outra variedade que não a padrão. Sendo 
assim, com o saber sociolinguístico acurado, essa informação deixa de ser uma fonte de conflito e passa a ser, portanto, espaço de reflexão, o que corrobora que tal domínio desfaria "a ordem como consequência da manipulação e do controle por parte dos grupos dominantes sobre os dominados" (MORENO FERNÁNDEZ, 2012, p. 43) e a mudanças na percepção das variedades seriam mais organizadas para os alunos.

Quanto à frequência dos desvios apresentados neste estudo, pode-se inferir que talvez estejam associados ao uso desenfreado do ambiente virtual e das redes sociais, nos quais verifica-se recorrentemente a presença de hábitos da fala na escrita, como os fenômenos fonológicos variáveis e graduais descritos neste artigo. Não se descarta, portanto, a hipótese de que o ambiente digital pode corroborar para o surgimento, inclusive pelo assentamento, destes desvios. No entanto, grande parte dos fenômenos encontrados nas redações escolares que reflete a influência da fala para a escrita, tem explicações históricas que transcendem a era moderna (SENE, 2018), o que acaba reiterando a importância de se compreender as regras variáveis da língua.

Nesse sentido, diante de processos como os aqui apresentados, o professor deve priorizar o trabalho com os recursos mais próximos que facilitem o aprendizado do aluno, neste caso, sua própria fala, fonte primária e incontestável, mesmo que a circulação desses desvios, na era digital, possa ser reforçada. Afinal, quando formulam hipóteses para a escrita, os alunos buscam na oralidade e no pouco conhecimento das convenções ortográficas as formas de representação da "escrita", o que gera um desvio ortográfico que reflete, muitas vezes, fenômenos variáveis. Por fim, destaca-se a importância do sexto princípio delineado por Bortoni-Ricardo (2005), já que é um ponto que reforça que o professor não deve se limitar a transmitir conhecimentos técnicos, que são produtos de pesquisas acadêmicas, mas que deve estabelecer um efetivo diálogo entre teoria e prática e, a partir disso, enriquecer e aprimorar suas próprias práticas e ações para que, então, possa valorizar e conscientizar o processo de ensino-aprendizagem do aluno.

AGRADECIMENTOS: À CAPES, pela bolsa durante a pesquisa de Sene (2018) e à Profa. Dra. Juliana Bertucci Barbosa, pela coorientação da pesquisa. 


\section{REFERÊNCIAS}

ABAURRE, M. B. M. O que revelam os textos espontâneos sobre a representaçãoque faz a criança do objeto escrito? In: KATO, M. A. (Org.). A concepção da escrita pela criança. Campinas: Pontes, 1988. p. 135-142.

BARONAS, J. E. de A. Marcas de oralidade no texto escrito. Signum: Estudos da Linguagem, v. 12, n. 1, p. 15-32, 2009.

BORTONI-RICARDO, S. M. Educação em língua materna: a sociolingüística na sala de aula. São Paulo: Parábola, 2004.

BORTONI-RICARDO, S. M. Nós cheguemu na escola e agora?. Sociolinguística \& Educação. São Paulo: Parábola, 2005.

BORTONI-RICARDO, S. M.; OLIVEIRA, T. de. Corrigir ou não variantes não padrão na fala do aluno. In: Os doze trabalhos de Hércules do oral para o escrito. São Paulo, Parábola, 2013. p. 45-62.

CALLOU, D.; MORAES, J.; LEITE, Y. Apagamento do $\mathrm{r}$ final no dialeto carioca: um estudo em tempo aparente e em tempo real. DELTA: Documentação de Estudos em Lingüística Teórica e Aplicada, SciELO Brasil, v. 14, n. esp., 1998.

CÂMARA-JR, J. M. Erros escolares como sintomas de tendências lingüísticas no português do rio de janeiro. Romanistiches Jahrburg, v. 8, p. 279-86, 1957.

CÂMARA-JR, J. M. Para o estudo da fonêmica portuguesa. Rio de Janeiro: Padrão, 1977.

ERICKSON, F. Transformation and school success: The politics and culture of educational achievement. Anthropology \& Education Quarterly, Wiley Online Library, v. 18, n. 4, 1987

HENRIQUE, P. F. de L.; HORA, D. da. Da fala à escrita: a monotongação de ditongos decrescentes na escrita de alunos do 30 ao 50 ano do ensino fundamental. Letrônica, v. 6, n. 1, p. 108-121, 2016.

GOMES, A. M. A influência da oralidade na escrita: uma análise sociolinguística sobre as redações escolares de uma escola pública do Distrito Federal. 2008. 215 f. Dissertação (Mestrado em Linguística) - Universidade de Brasília, Brasília, 2008.

FERNÁNDEZ MARRERO, J. J. Actividad normativa y conciencia lingüística: los problemas de la prescripción idiomática. São Paulo: LGN, 2004.

LABOV, W. Padrões sociolinguísticos. São Paulo: Parábola Ed., 2008 [1972].

MARCUSCHI, L. A. Oralidade e escrita. Signótica, v. 9, n. 1, p. 119-146, 1997.

MARCUSCHI, L. A. Da fala para a escrita: atividades de retextualização. São Paulo: Cortez Editora, 2000. 
MOLLICA, M. C. Influência da fala na alfabetização. [S.1.]: Tempo Brasileiro, 1998.

MORAIS, A. G. de. O aprendizado da ortografia. São Paulo: Ática, 2003.

MORENO FERNÁNDEZ, F. Sociolingüística cognitiva: proposiciones, escolios y debates.

Madri/Frankfurt: Iberoamericana - Vervuert, 2012.

OLIVEIRA, M. B. de. Manutenção e apagamento do /R/ final de vocábulo na fala de

Itaiuba. 2001. Dissertação (Mestrado) - Universidade Federal do Pará, Belém, 2001.

SENE, M. G.; ORANGES, C. S. Fala[ø] e Escreve [ø]: variação do rótico em posição de coda na escrita escolar de Uberaba/MG. Revista Entrepalavras, v. 7, p. 165-181, 2017.

SENE, M. G. Os desvios ortográficos de redações escolares do Ensino Fundamental II descrição, análise e atitudes linguísticas dos professores. 2018. 178 f. Dissertação (Mestrado em Linguística e Língua Portuguesa) - Universidade Estadual Paulista, Araraquara, 2018.

SENE, M. G.; BARBOSA, J. B. Quando a oralidade chega à escrita: discutindo os desvios ortográficos em textos do Ensino Fundamental II de Uberaba/MG. A COR DAS LETRAS (UEFS), v. 19, p. 7, 2019.

\section{Como referenciar este artigo}

SENE, Marcus Garcia de; SANDES, Egisvanda Isys de Almeida. Análise de alguns traços fonológicos graduais na escrita sob a perspectiva da sociolinguística educacional. Rev. EntreLínguas, Araraquara, v. 6, n. 1, p. 167-182, jan./jun. 2020. e-ISSN: 2447-3529. DOI: https://doi.org/10.29051/el.v6i1.13326

Submetido em: 30/07/2019

Revisões requeridas: 30/08/2019

Aprovado em: 30/11/2019

Publicado em: 06/01/2020 